As far as the material was concerned, they produced acceptable accounts of the formulation and mental state of a particular patient. They used two mnemonics, the first of which, IDJIMP, was unmemorable, while the second, ACTMAD, did have a quality to it which may help to lay it down in long-term memory. Even this was spoilt by the apologetic explanation that $D$ really stood for organic but did not fit the mnemonic.

One could not in all honesty say that this tape could be commended, other than for purely local use, thus giving the lecturer an 11-minute break before returning to explain and elaborate various points that are made.

Production: Leeds University Audio-Visual Service, Leeds LS2 9JT (Presenter: Dr. S. Baugh). Available for sale on all formats.

C. P. SEAGER

University of Sheffield

\title{
Mental Health and the Media
}

\section{Channel 4}

From September to December 1986 Channel 4 is presenting a season of programmes on mental health themes. Titles include:

Schizophrenia and the community-about people who have been diagnosed schizophrenic but are finding ways of living in the community.

Race and mental health-an examination of how black and Asian people are treated by the mental health 'establishment'.

Museums of madness-a series of three very different programmes which raise questions about our attitudes to mental illness and how they have been reflected historically. $A$ change of mind-a series about therapy.

Voices-this series which is regularly broadcast looks at psychoanalyses.

We're not mad... we're angry-a documentary/drama programme which aims to show that psychiatry is a means of social control. It is made entirely from the perspective of those people who have been treated by psychiatrists.

For further information about any of the programmes, contact: Derek Jones, Education Liaison Officer, Channel 4, 60 Charlotte Street, London WIP 2AX

\section{BBC-Education}

In January 1987 the BBC Continuing Education department begins a series of eight 10 minute films, YOU IN $M I N D$, for transmission on Sundays at a time between 6.00 and 6.30 p.m. This slot, at a popular time, can sometimes reach as many as eleven million people.

The series is not about mental illness but aims to prevent ill health. It will take a practical approach with each programme showing good and bad coping strategies to encourage self help. It will hope to give people the feeling that they have control over their own mental health, and give useful information and sources which will help them to do this.

\section{Individual programmes will look at:}

Insomnia, Anxiety, Depression, Expressed Feelings-learning to say what you feel and how to be a good listener, Time Pressure - how to avoid stress at home and at work, Assertiveness Training, Drug Taking - tranquillisers and antidepressants and their dangers, Mind and Body-an attitude changing programme featuring latest research which demonstrates mind and body unity and the approach of complementary therapy.

More information can be obtained from Angie Mason, Senior Education Officer, Continuing Education, BBC, Villiers House, The Broadway, London W5 2PA

\section{North West Fellowship}

This Fellowship gives advice and assistance to sufferers from schizophrenia and their families who live in the North West of England and aims to advance public understanding of the nature of schizophrenia. It runs day centres and housing and employment schemes and is developing self- help groups of sufferers and their relatives throughout the region. Further information: North West Fellowship for the Support of Schizophrenia Sufferers and their Families, 46 Allen Street, Warrington, Cheshire WA2 7JB (telephone 0925 571680). 